\title{
Get Involved: Qizhen Li, TMS Young Leader Professional Development Award Winner
}

\author{
Kelly Zappas
}

"Get Involved" spotlights the work of TMS volunteers and shows the wide range of activities available through the society. This month, Qizhen Li, assistant professor in the Chemical and Materials

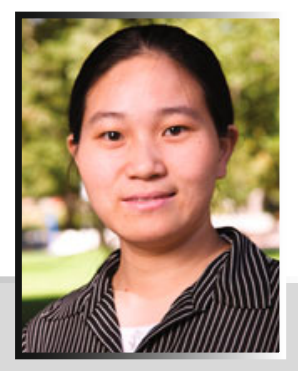
Engineering Department at the University of Nevada, Reno, discusses her experiences as a 2012 TMS Young Leader Professional Development Award winner. The award provides funding for professional TMS members under the age of 40 to attend a TMS Annual Meeting and participate in high-level meetings of TMS leadership. TMS will accept applications for the 2013 award through September 15. For more information, visit http://www.tms.org/YoungLeaders/YLintern.aspx.

Q. Prior to winning the Young Leader Professional Development Award, what was your experience with TMS?

A. Prior to winning this award, I attended TMS meetings on a regular basis to present research findings and organize technical symposia. I became a student member in 2001 and have been a professional member since 2006.

Q. As part of the Young Leader Professional Development Award, you had the opportunity to attend the TMS 2012 Annual Meeting and participate in the board of directors meeting. What did you learn from this experience?

A. This was my first time attending the board of directors meeting. It was a great eye-opening experience and allowed me the in-person observation on how the collaborative efforts of directors contribute to the TMS society. The directors were from academia, industries, national labs, and so on. They represented the diverse backgrounds of TMS members and TMS conference attendees.

Q. You were awarded this opportunity by the TMS Light Metals Division (LMD). Did this experience help you to become more involved in TMS's light metals activities?

A. Yes. I had the experience for the first time to attend the LMD Council meeting and the LMD Luncheon, which were great opportunities to learn the variety of activities the LMD leads. The division chair and TMS staff are always helpful with introducing and involving young professionals in the division activities. The division councilors are highly devoted to the division's development.

Q. What was the most valuable aspect of the experience for you?

A. All of the arranged activities were of high value. Among them, the ones that impressed me the most were the board of directors meeting and the technical division council meeting. Attending these meetings allowed me to learn about all the efforts of the directors and the councilors devoted to the development and prosperity of TMS.

Q. Did the award help you to meet other young professionals in your field?

A. Yes. The activities arranged for the awardees were great channels for us to meet other young professionals. The awardees also met and interacted with each other while attending the arranged activities. The TMS2012 Volunteer Leadership Lounge provided young professionals a nice location to meet and communicate with each other.

Q. Do you plan to become more involved in TMS activities as a result of this experience?

A. Yes. I am involved in various TMS activities. I became the secretary of the Young Leader Committee and hope to better serve TMS. The Young Leader Committee is actively working for the society through conducting various duties such as organizing the Young Leader Career Panel and the Young Leader Meet the Candidate Poster Session. These activities should be able to help with the development of young professionals in both academic and industrial organizations.

Q. Would you encourage other young professionals to apply for the Professional Development Award? If so, why?

A. Yes. It is obviously great for young professionals to have the opportunity to attend various activities, especially the board of directors meeting, through this award. These activities provide training opportunities for future leaders and benefit young professionals' careers.

Kelly Zappas is a contributing writer for JOM. 